\title{
Research on Creep Test for Reinforced Concrete Frame Structure
}

\author{
Zhong-Yi LI 1, 2a, Qing-Qing SHEN1, 2b, Ying-She LUO', 2c*, \\ Song-Hue TANG 3, d, Yan-ZHANG 3, e, Yu-Peng CUl3,f \\ ${ }^{1}$ Institute of Rheological Mechanics and Materials Engineering, \\ Central South University of Forestry and Technology, Changsha 410004, Hunan, China \\ ${ }^{2}$ Hunan Province Key Laboratory of Engineering Rheology, \\ Central South University of Forestry and Technology, Changsha 410004, Hunan, China \\ ${ }^{3}$ School of Civil Engineering, Central South University, Changsha 410075, Hunan, China \\ a263797728@qq.com, bsqqshen1994@sina.com, 'lys0258@vip.sina.com(Corresponding author),

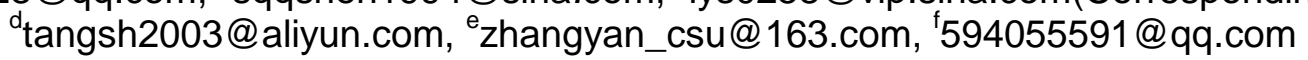

\begin{abstract}
Keywords: reinforced concrete frame structure, fire test, creep test, rheological property Abstract. The fire tests included fire load and fire temperature had been conducted to twelve reinforced concrete frame structures with ISO834 standard heating up curve. Furthermore, the creep tests had also been done under room temperature to the above twelve structures after cooling and one structure which with the same shape and size but had not undergone the fire test. According to the creep data, the creep curves of each specimen were obtained, the rheological properties of the structures after fire tests were simply discussed as well. The experiments showed that the fire temperature effect on the specimen was larger than the fire load, the higher temperature the specimen suffered, the more it looked like a standard creep curve. When the fire temperature was $600^{\circ} \mathrm{C}$, only the first two stages (the initial creep stage and the steady creep stage) of the creep behavior were obtained. While the third stage (the accelerated creep stage) were clearly presented when the fire temperature was $1000^{\circ} \mathrm{C}$.
\end{abstract}

\section{Introduction}

Fire causes heavy loss of life and property safety to human beings each year. Statistics showed that building fire [1] is one of the most frequent and devastating disasters in the nature. Therefore, study the fire resistance of reinforced concrete structures, on one hand is to establish a set of reasonable and convenient method for fire resistance design, on the other hand is to make scientific and accurate evaluation for the damage degree of building structure, to assure the safety of people's life, reduce fire loss, shorten the function recovery time of the structure.

The study of reinforced concrete structure under high temperature abroad were earlier than the domestic scholars[2-4], many design theories and analyses methods about the fire resistance of reinforced concrete had been built by the research on stress distribution, action of deformation and failure characteristics of structure under high temperature. Domestic Xu-dong Shi, Zhen-hai Guo [5] took five pin framework for fire test on three sides, they got the appeared rule of plastic hinge, the destructive mechanism of the framework under the high temperature. Ying-she Luo, Chao Chen etc. [6] obtained the change laws of concrete strength under high temperature by compression test about concrete specimens under different temperature degrees; Song-hua Tang, Ying-she Luo, Chao Chen etc. [7] built the thermal damage model about concrete under high temperature by introduced "residual intensity" as independent damage variable; Xuan Zhang [8] obtained the ultimate bearing capacity of reinforced concrete frame structures after fire by static load tests on corresponding specimens. In general, experimental research on reinforced concrete frame structure under and after fire was less, let alone the contrast creep tests to the structures without and undergone fire tests.

According to the fire tests in reference [8], in this paper, the fire tests with fire load and fire temperature for twelve reinforced concrete frame structures with corresponding fixed steel supports 
had been conducted. Then, for comparison, the contrast creep tests in room temperature to the structures with the same shapes and sizes had also been finished. The influence of the temperature on the rheological properties of the structure had been simply discussed. According to the datum form the later creep tests, a corresponding creep model (improved Burgers model) [9] was built. Origin 7.5 was used to find out whether the model can fit the experimental datum well or not. There are some important conclusions which can be partly applied to fire resistance evaluation of concrete structure.

\section{The Summary of Test}

The Parameters of Test. Ordinary Port-land cement numbered 42.5, longitudinal reinforcement numbered HRB335 and hooped reinforcement numbered HRB235 were used for making the reinforced concrete specimens. The proportion of concrete was: cement: water: sand: stone was equal to 1: $0.617: 2.257: 4.127$. The form and sizes, reinforcement and load of specimen, were shown in Fig.1.

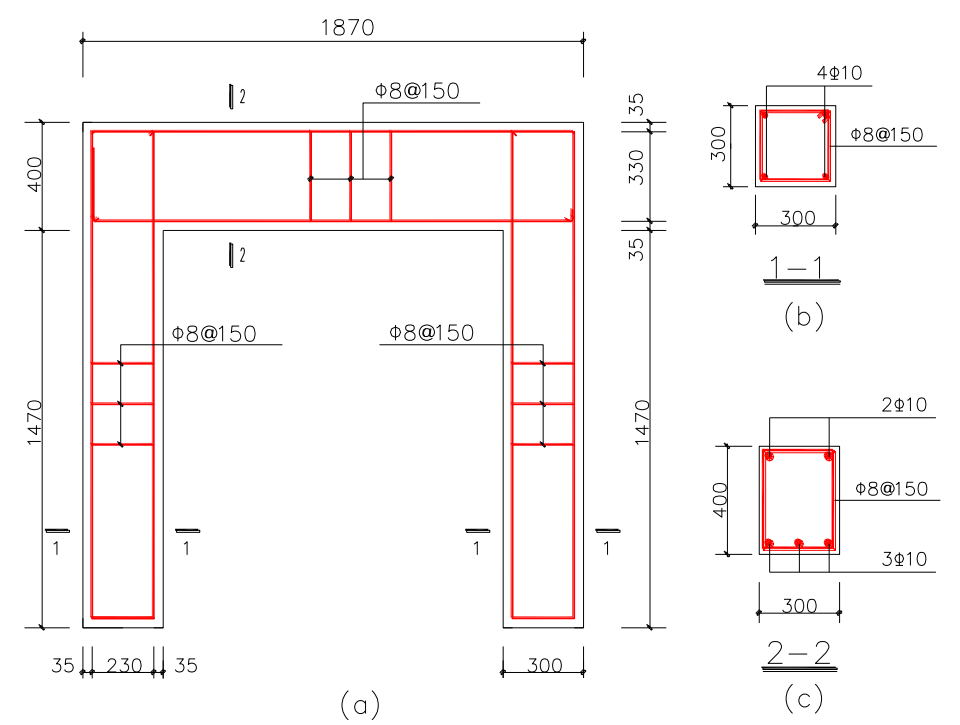

(a) Form of specimen (b) Reinforcement of 1-1 cross-section (c) Reinforcement of 2-2 cross-section Fig.1 Form and sizes of the reinforcement concrete structure specimen

The Conditions parameters of Test. In the fire test, the specimens had been tested by fire furnace in Railway Institute of Central South University, 15 specimens of reinforced concrete frame with corresponding steel braces were made for the tests. One framework for normal temperature test and two in reserve, the remaining twelve specimens were used in the fire tests. Five sides named front, behind, left, right and bottom surface of specimen were suffered from fire. ISO834 standard heating up curve was used in the test, when the expected temperature reached, it should be kept at the temperature for 2 hours. Three different temperature levels and four different load levels were applied to the twelve specimens respectively. The specimens condition parameters were shown in Table 1.

Table.1 Fire condition parameters of the fire tests

\begin{tabular}{lrrrrrrrrrrrr}
\hline Specimen number & $\mathrm{T}_{1}$ & $\mathrm{~T}_{2}$ & $\mathrm{~T}_{3}$ & $\mathrm{~T}_{4}$ & $\mathrm{~T}_{5}$ & $\mathrm{~T}_{6}$ & $\mathrm{~T}_{7}$ & $\mathrm{~T}_{8}$ & $\mathrm{~T}_{9}$ & $\mathrm{~T}_{10}$ & $\mathrm{~T}_{11}$ & $\mathrm{~T}_{12}$ \\
\hline Test temperature $\left({ }^{\circ} \mathrm{C}\right)$ & 600 & 800 & 1000 & 600 & 800 & 1000 & 600 & 800 & 1000 & 600 & 800 & 1000 \\
Static load value $(\mathrm{kN})$ & 21 & 21 & 21 & 28 & 28 & 28 & 35 & 35 & 35 & 42 & 42 & 42 \\
\hline
\end{tabular}

The Creep Tests and Creep Curves After the fire test, remove the specimen out of the furnace to cool it to room temperature naturally, then the creep tests were done by using 500t hydraulic jack among the fired twelve specimens and the one without fire. The loading method was two-points loading, the hydraulic jack was between the steel frame and the assistant beam which transferred the load to the specimen with two cushion blocks. The cushion blocks were located at $1 / 3,2 / 3$ point of the 
frame girder respectively. During the creep tests, the changes of the midspan deflection about the specimen with time increased were measured by dial indicator which fixed at the bottom of the frame girder. The data were recorded automatically by the machine, as well as the creep curves. The experimental methods were shown in Fig.2.

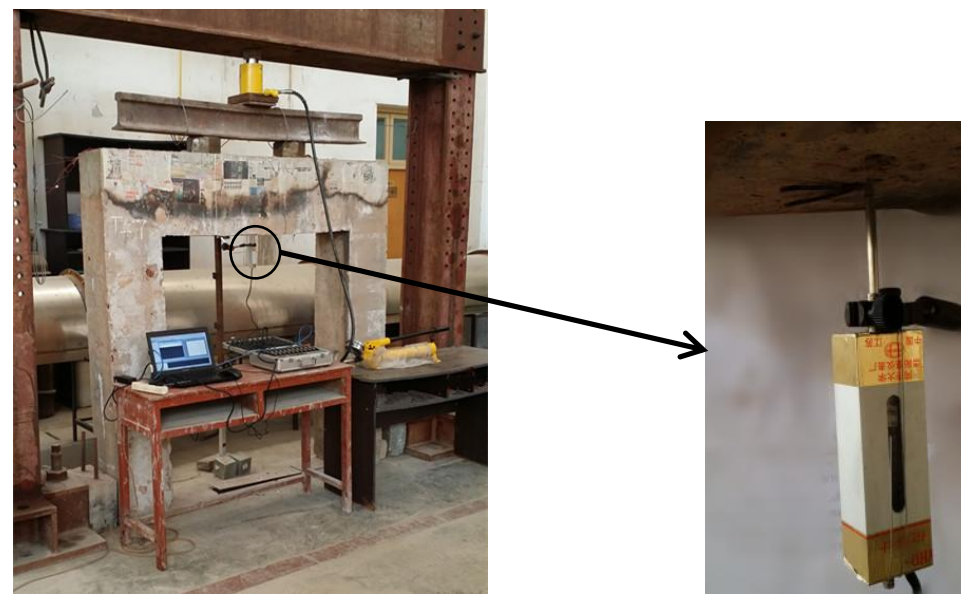

(a) Loading method

(b) Deflection measurement

Fig.2 Experimental method

The creep curves were shown in Fig.3, among which the residual creep deformation of the specimen was also measured in (a), (b), and (c).

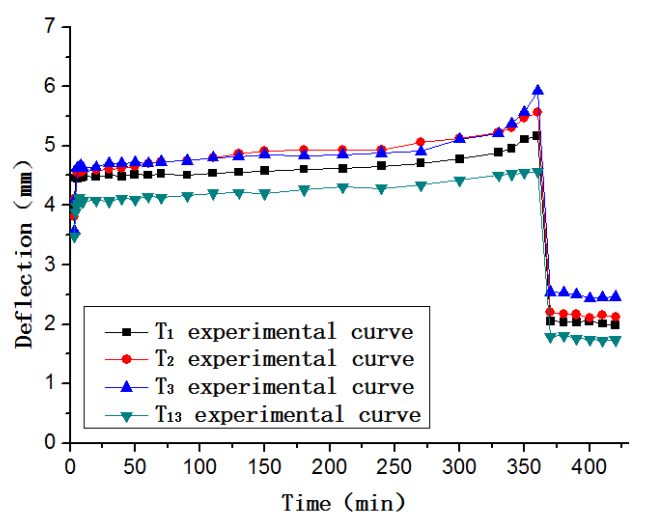

(a) The creep curves of spacemen $T_{1}, T_{2}, T_{3}, T_{13}$

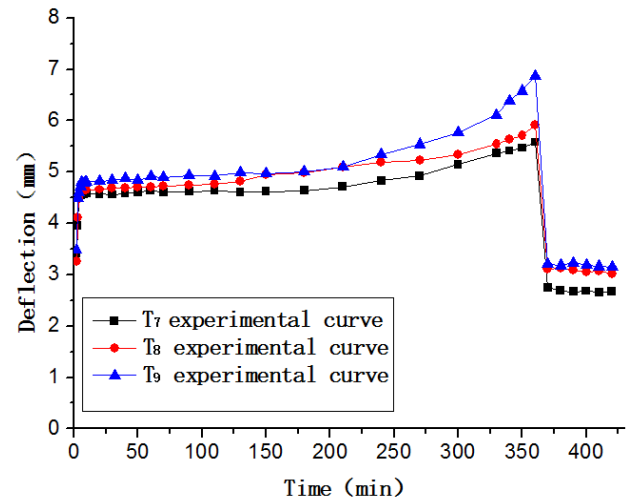

(c) The creep curves of spacemen $\mathrm{T}_{7}, \mathrm{~T}_{8}, \mathrm{~T}_{9}$

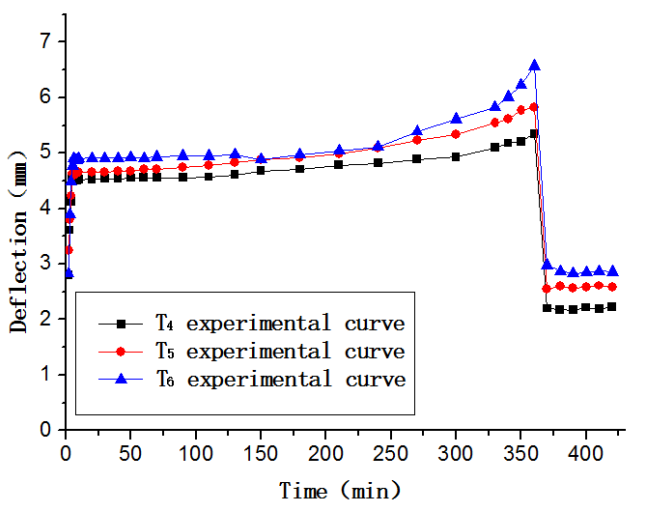

(b) The creep curves of spacemen $\mathrm{T}_{4}, \mathrm{~T}_{5}, \mathrm{~T}_{6}$

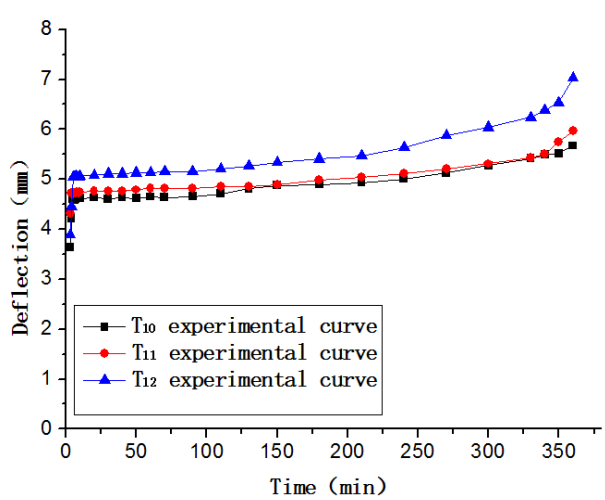

(d) The creep curves of spacemen $\mathrm{T}_{10}, \mathrm{~T}_{11}, \mathrm{~T}_{12}$

Fig. 3 The creep curves of all spacemen after fire under room temperature

\section{Analysis of Test Results}

Constant static loads were applied during the creep tests, the loads values were depended on reference [8]'s ultimate bearing capacity values multiplied by $75 \%$. The static load value and the residual creep deformation values after creep tests were recorded in Table 2. 
Table 2 Loads and residual deformation of the creep tests

\begin{tabular}{cccccccccccccc}
\hline \multicolumn{1}{c}{ Specimen number } & $\mathrm{T}_{1}$ & $\mathrm{~T}_{2}$ & $\mathrm{~T}_{3}$ & $\mathrm{~T}_{4}$ & $\mathrm{~T}_{5}$ & $\mathrm{~T}_{6}$ & $\mathrm{~T}_{7}$ & $\mathrm{~T}_{8}$ & $\mathrm{~T}_{9}$ & $\mathrm{~T}_{10}$ & $\mathrm{~T}_{11}$ & $\mathrm{~T}_{12}$ & $\mathrm{~T}_{13}$ \\
\hline Static load value $(\mathrm{kN})$ & 177 & 139 & 122 & 168 & 129 & 111 & 151 & 142 & 104 & 140 & 110 & 100 & 262 \\
Residual deflection $(\mathrm{mm})$ & 2.0 & 2.1 & 2.4 & 2.2 & 2.6 & 2.9 & 2.7 & 3.0 & 3.2 & $/$ & $/$ & $/$ & $/$ \\
\hline
\end{tabular}

The Effects of Temperature on the Creep Development of Frame Specimen. From Fig.3, one could see that, before the creep test, the higher temperature the specimen suffered, the more it looked like a standard creep curve with three stages. When the fire temperature was $600^{\circ} \mathrm{C}$, only the first two stages (the initial creep stage and the steady creep stage) of the creep behavior were obtained. When the fire temperature increased to $1000^{\circ} \mathrm{C}$, the third stage (the accelerated creep stage) was clearly presented in the tests. In other words, specimens suffered with higher temperature, $\operatorname{likeT}_{3}, T_{6}, T_{9}, T_{12}$, the lower the bearing capacity was, the weaker the structure resist the instability caused by creep.

The Creep Model and the Fitting Curves. From Table 3 and Fig.3, one could see that the process of creep contains plastic deformation apparently, the improved Burgers model was chosen as it contains a plastic component which can reflect material's plastic property, and its structure drawing was shown in Fig.4.

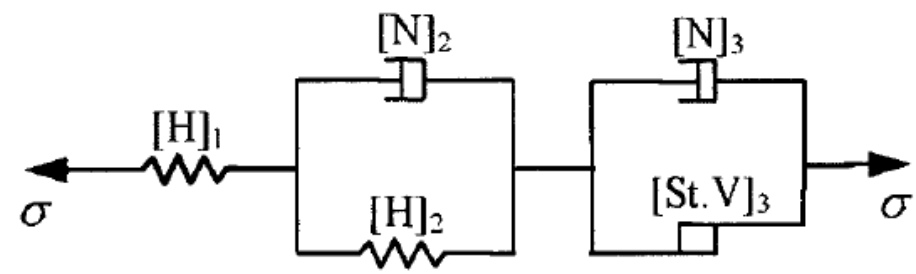

Fig.4 Structure drawing of improved Burgers model

The creep equation of the model was shown in Eq.1, which could be simplified as Eq.2, $a, b, c$, and $d$ were four parameters.

$$
\begin{aligned}
& \varepsilon(t)=\frac{\sigma}{E_{1}}+\frac{\sigma-\sigma_{s}}{\eta_{3}} t+\frac{\sigma}{E_{2}}\left[1-\exp \left(-\frac{E_{2} t}{\eta_{2}}\right)\right] \sigma>\sigma_{s} . \\
& y=a+b t+c[1-\exp (-d t)] .
\end{aligned}
$$

The software Origin 7.5 was used to fit the creep equation with the creep datum. The results were shown in Fig.6. In it one can see that the improved Burgers model can fit the specimens such as $\mathrm{T}_{1}, \mathrm{~T}_{4}$, $\mathrm{T}_{7}, \mathrm{~T}_{10}, \mathrm{~T}_{13}$ well, these specimens suffered a lower temperature in the fire tests before the creep tests, only the first two stages of the creep behavior were appeared in their creep curves, so as to the untreated specimen $\mathrm{T}_{13}$. When the fire temperature increased to $1000^{\circ} \mathrm{C}$, such as specimens like $\mathrm{T}_{3}, \mathrm{~T}_{6}$, $\mathrm{T}_{9}, \mathrm{~T}_{12}$, their creep curve contains all the stages of standard creep curve, especially the third stage (the accelerated creep stage) which makes it difficult to fit with the chosen creep model. In conclusion, the improved Burgers model can fit the first two stages of creep well, but as the creep developed, especially when the accelerated creep stage appeared, the fitted results became not so well. 


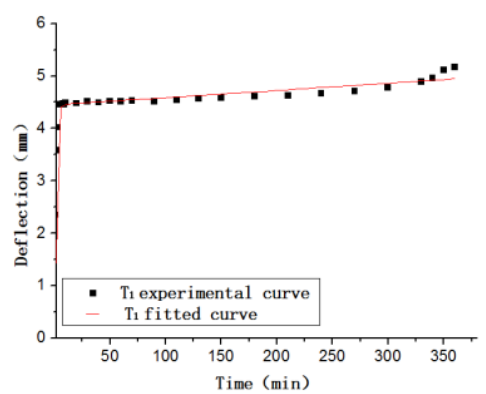

(a) Fitted curve of $T_{1}$

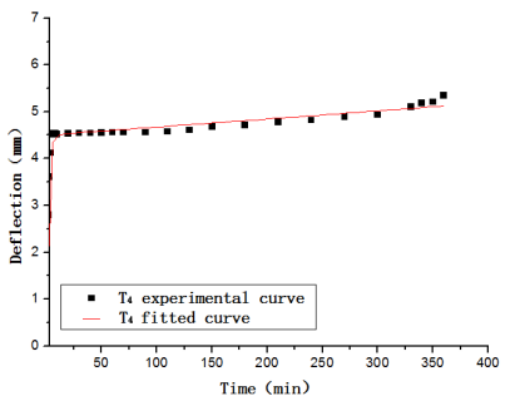

(d) Fitted curve of $T_{4}$

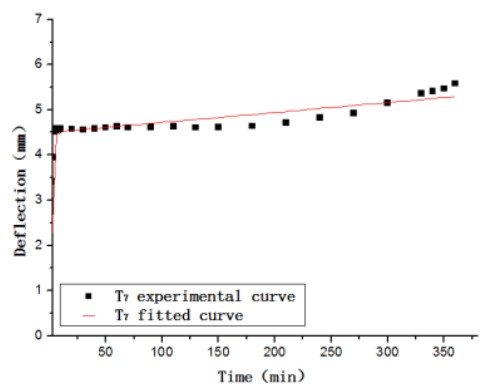

(g) Fitted curve of $T_{7}$

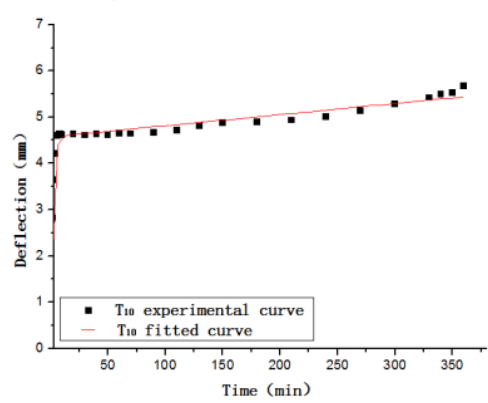

(j) Fitted curve of $T_{10}$

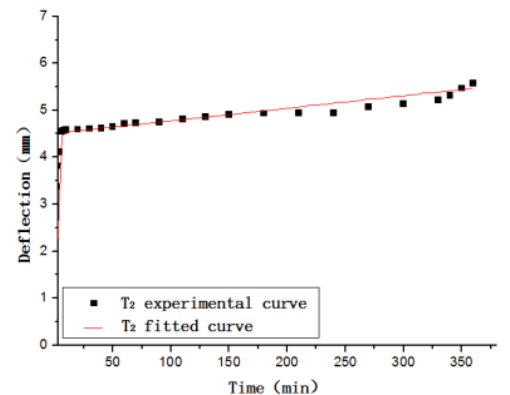

(b) Fitted curve of $T_{2}$

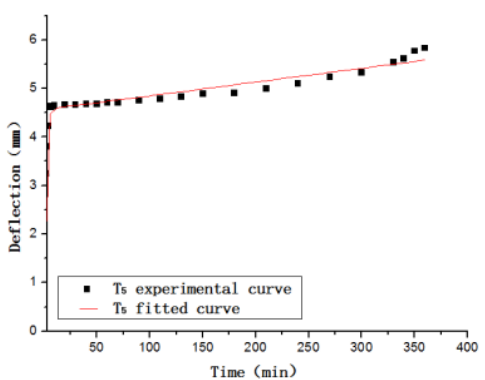

(e) Fitted curve of $T_{5}$

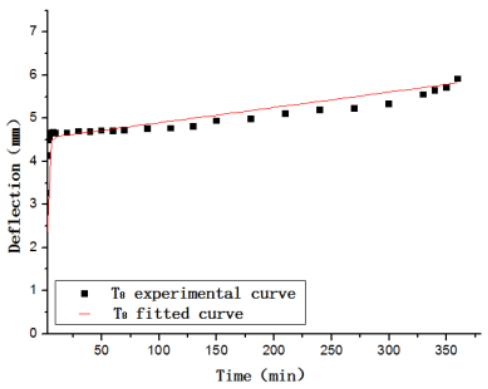

(h) Fitted curve of $T_{8}$

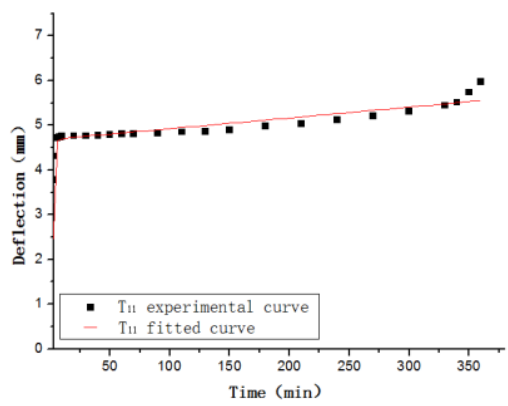

(k) Fitted curve of $T_{11}$

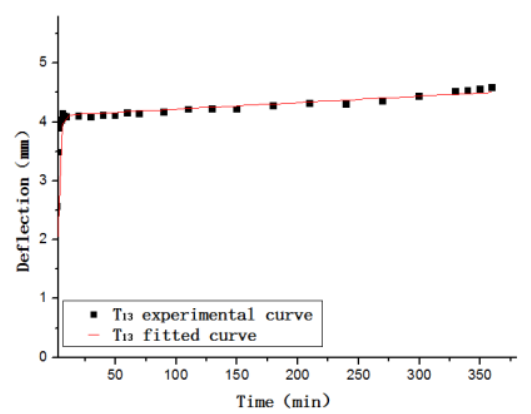

(m) Fitted curve of $T_{13}$

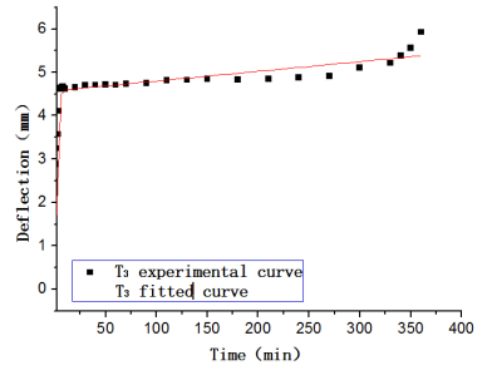

(c) Fitted curve of $T_{3}$

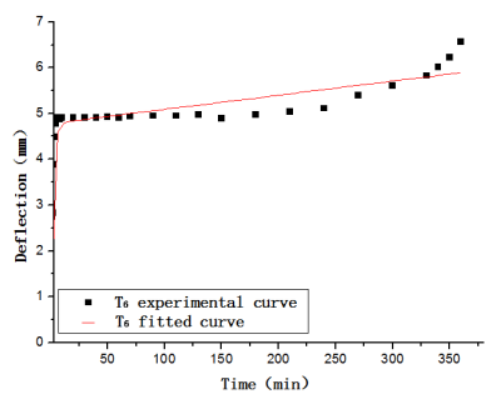

(f) Fitted curve of $T_{6}$

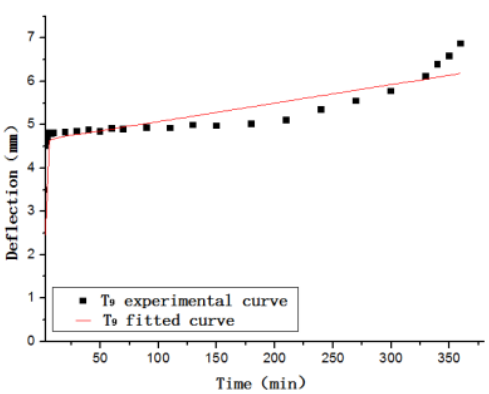

(i) Fitted curve of $T_{9}$

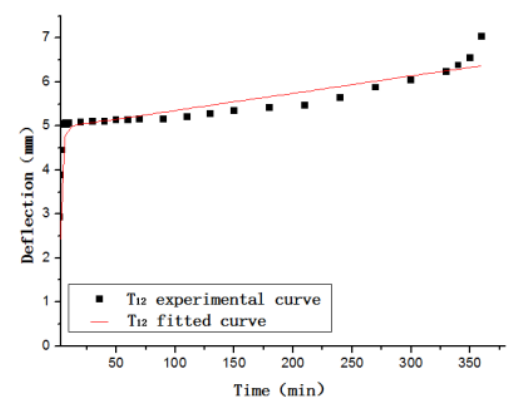

(1) Fitted curve of $T_{12}$

Fig.5 Fitted curves of each specimen 


\section{Summary}

(1) The change of the performance of reinforced concrete frame structure after fire test showed that before the creep test, the higher temperature the specimen suffered, the better the creep curve shaped like a standard creep curve which contained the whole three stages. When the fire temperature was $600^{\circ} \mathrm{C}$, only the first two stages (the initial creep stage and the steady creep stage) of the creep behavior were appeared. When the fire temperature increased to $1000^{\circ} \mathrm{C}$, the third stage (the accelerated creep stage) was clearly presented in the tests. In other words, higher temperature could make it easier to lose the resistance to deformation even though the creep-load is much smaller.

(2) The improved Burgers model can fit the first two stages of creep curve well, but as the creep developed, when the accelerated creep stage appeared, the fitting results became not so well.

(3) Take specimens $T_{1}, T_{2}, T_{3}$ in comparison, their creep loads were $177 \mathrm{kN}, 139 \mathrm{kN}$ and $122 \mathrm{kN}$ respectively, while their deflections at 350 minutes after creep tests were $5.17 \mathrm{~mm}, 5.57 \mathrm{~mm}, 5.93 \mathrm{~mm}$ respectively. We can see that specimen $T_{3}$ 's deflection was the biggest while its creep load was the smallest, as it ever suffered a highest temperature. In brief, higher temperature damaged the structure itself, so that the damaged structure might lead to a larger deflection at a lower load in a certain time.

\section{Acknowledgments}

This work was financially supported by National Natural Science Foundation (51178474).

\section{References}

[1] Y.L. Dong: Xiangshan Science Conference Vol. 2 (1997), p. 35 (In Chinese).

[2] J.M. Becker and B. Bresler: Reinforced Concrete Frames in Fire Environments. (ASCE, American 1977).

[3] T.T. Lie, R.J. Irwin: ASCE Vol. 5 (1995), p. 797.

[4] N.J.K. Cameron: The Behaviour and Design of Composite Floor Systems in Fire. (A Dissertation for Doctor of Philosophy, University of Edinburgh 2003)

[5] X.D. Shi, Z.H. Guo: China Civil Engineering Journal Vol. 6(2000), p. 6 (In Chinese).

[6] Y.S. Luo, C. Chen etc.: Natural Science J. of Xiangtan University, Vol. 2 (2013), p. 30 (In Chinese).

[7] S. H. Tang, Y. S. Luo, C. Chen, etc., Advanced Materials Research, Vols.639-640 (2013), 1193.

[8] X. Zhang: Experimental Study on Fire Resistance of Full Scale Reinforced Concrete Frame Structure (A thesis of Central South University of Forestry and Technology, Changsha 2015).

[9] Y.S. Luo: The Theoretical Vxperimental and Practical Research on Rheological Forming of Metals (A thesis of National University of Defense Technology, Changsha 2000). 